\title{
Recurrent Pleomorphic Adenoma of the Submandibular Gland
}

\author{
Serhat İnan ${ }^{1}$, Erdinç Aydın ${ }^{1}$, Seda Türkoğlu Babakurban ${ }^{1}$, Eda Yılmaz Akçay ${ }^{2}$ \\ Case Report $\ \begin{aligned} & { }^{1} \text { Department of Otorhinolaryngology, Başkent University School of Medicine Hospital, Ankara, Turkey } \\ & { }^{2} \text { Department of Medical Pathology, Başkent University School of Medicine Hospital, Ankara, Turkey }\end{aligned}$
}

Abstract

Pleomorphic adenoma (PA) is the most common benign tumor of salivary glands. Most PAs occur in the parotid (80\%), followed by the submandibular gland (10\%) and minor salivary and sublingual glands (10\%). Submandibular gland PAs usually manifest in the submandibular area as a painless hard mass. Although several recurrent parotid gland PA cases have been reported in the literature, recurrent submandib- ular gland PA is quite rare. Complete surgical removal of tumor of the submandibular gland and keeping the capsule intact are important to prevent recurrence. Here we present a rare case of submandibular gland PA recurrence that occurred 5 years after the first surgery and methods to prevent recurrence.

Keywords: Submandibular gland, pleomorphic adenoma, surgery

\section{Introduction}

Pleomorphic adenoma (PA) is the most common benign tumor of salivary glands. The tumor can also be classified as a mixed tumor due to its epithelial and mesenchymal components. In all, $80 \%$ of PAs occur in the parotid, $10 \%$ in the submandibular gland, and $10 \%$ in the minor salivary and sublingual glands. PAs of the submandibular gland are more common among women between 40 and 60 years of age. They usually present in the submandibular area as a painless hard mass. Histologically, PA is encapsulated by a thin capsule that forms around the salivary gland parenchyma due to fibrosis secondary to mass effect, which is also known as a pseudocapsule. The standard treatment for these tumors is surgical excision $(1,2)$. In recurring PA, there have been different hypotheses put forth based on histopathological and genetic factors. These are pseudopods in the capsule, incomplete capsule, satellite nodules, early development, stroma-rich variant, insufficient surgical procedure, and tumor implantation during surgical procedure (3-6). In this case report, we aim to discuss the reasons of rare submandibular gland PA recurrence and methods to prevent recurrence.

\section{Case}

A 32-year-old female patient presented with a painless swelling in her right submandibular region. She had been operated in another hospital 5 years earlier for the same complaint. Histopathological examination of the excised right submandibular gland revealed PA. Ultrasonography (US) of the neck revealed multiple $12 \mathrm{x} 9 \mathrm{~mm}$ solid hypoechoic lesions with defined contours at the previous resection site. These lesions were hypovascular, but had heterogeneous perfusion patterns. Elastographic analysis showed lesions with mid-solidity (strain ratio: $1.25-2.25)$. Neck magnetic resonance imaging (MRI) showed an approximately 40x22 $\mathrm{mm}$ lesion with multiple solid nodular lesions localized at the submandibular gland, the largest being $12 \times 10 \mathrm{~mm}$, which was enhanced by the contrast agent. These images resembled a "potato sack" (Figure 1,2). These nodules were hypointense with T1A and hyperintense with T2A enhanced analysis. Fine needle aspiration biopsy (FNAB) was performed and cytopathological examination confirmed PA.

The patient underwent mass excision and neck dissection at levels $1,2 \mathrm{a}, 2 \mathrm{~b}$, and 3 . A well-defined 


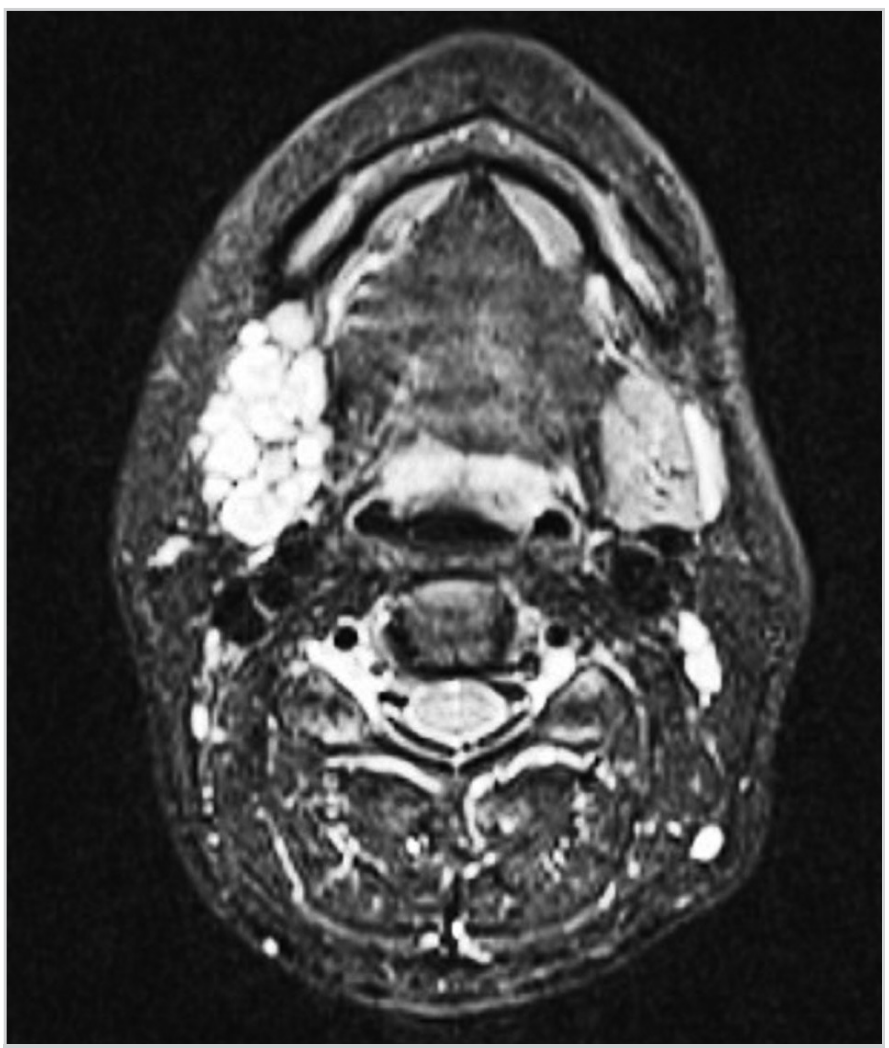

Figure 1.T2 axial MR images of tumor in the right submandibular area resembling a potato sack

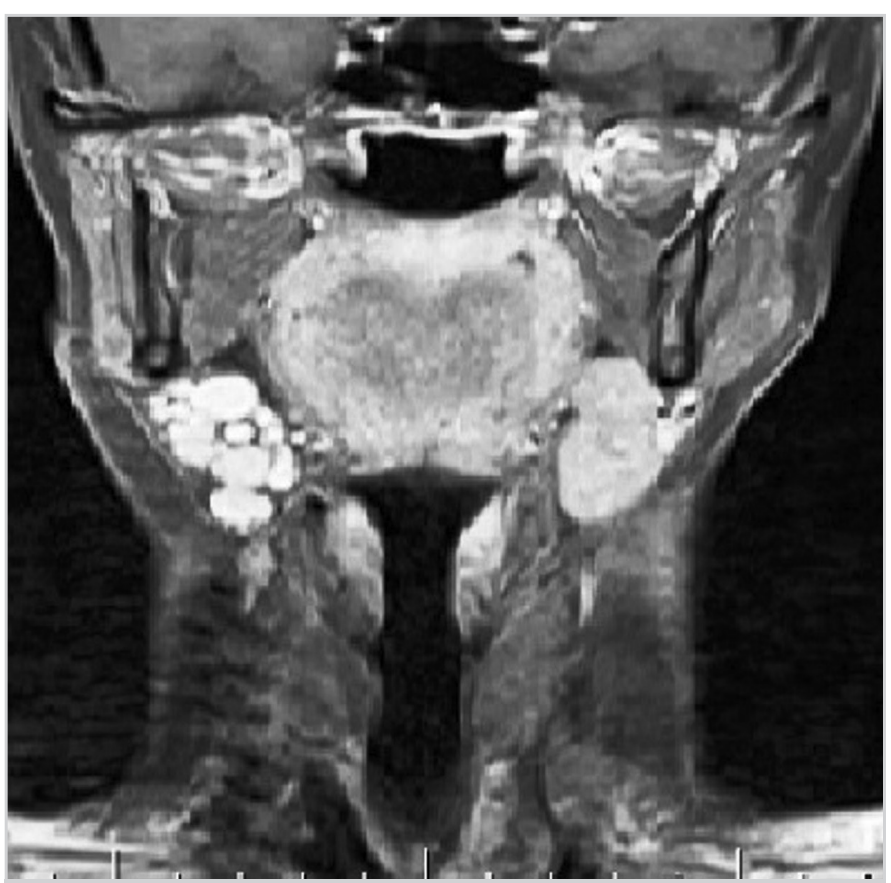

Figure 2.T2 coronal MR images of tumor in the right submandibular area resembling a potato sack

5-cm mass with solid features was identified at level 2a. In addition, a mass was dissected at the digastric muscle level while preserving the hypoglossal nerve. Marginal mandibular branch of the facial nerve was paralytic prior to operation, and during the operation, marginal branch of the facial nerve was not observed. Histopathological examination revealed that the multi-

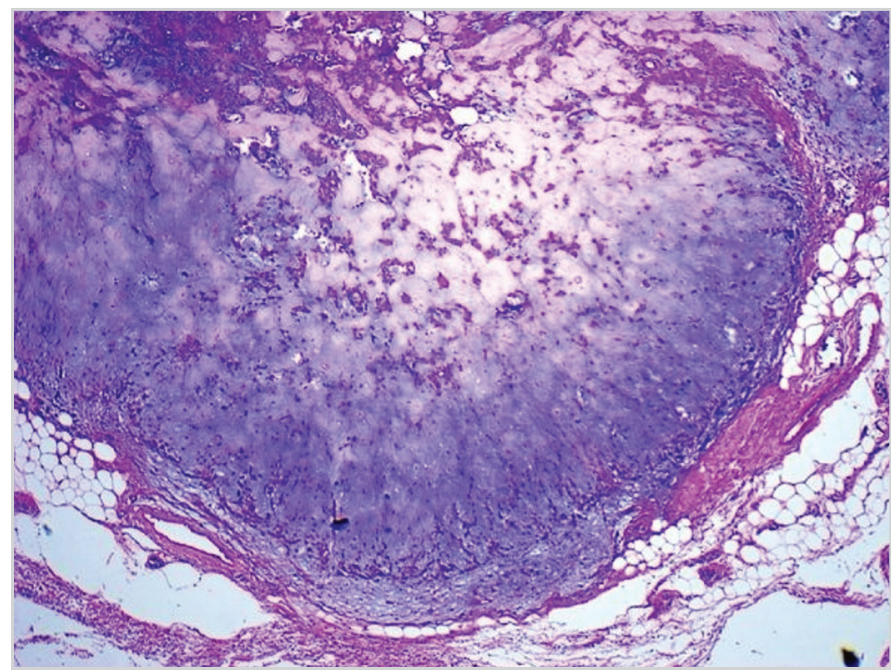

Figure 3. $(H \& E \times 100)$ Recurrent pleomorphic adenoma within adipose tissue demonstrating nodular development

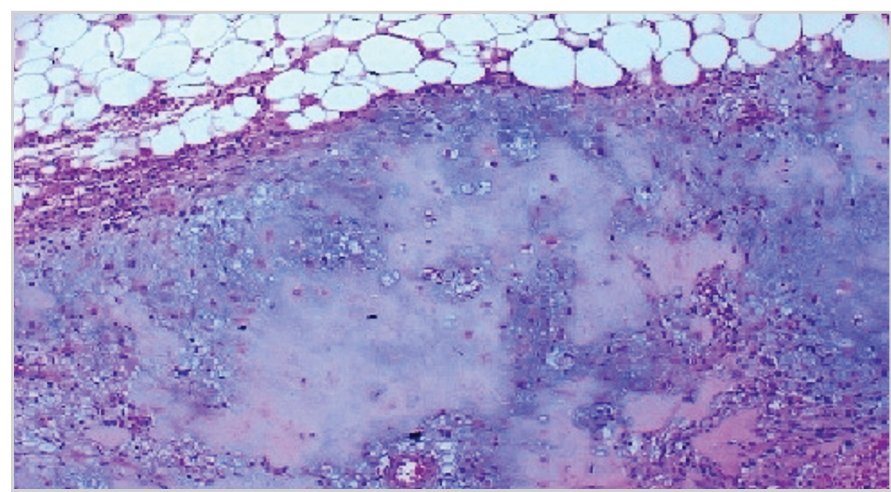

Figure 4. $(H \& E \times 200)$ Tumor with chondromyxoid stroma and myoepithelial cellular areas. Focal ductal differentiation is observed

ple tan-white nodular tissue fragments with attached adipose tissue (ranging from $0.2 \mathrm{~cm}$ to $1.5 \mathrm{~cm}$ ) were PAs (Figure 3, 4). In addition, 12 reactive lymph nodes were identified. The patient was asymptomatic and residual tumor tissue or recurrence was not observed at the 1-year follow-up.

\section{Discussion}

Salivary gland tumors constitute $3 \%-4 \%$ of the head and neck cancers, of which, $8 \%-22 \%$ are seen in the submandibular gland. Approximately $50 \%-57 \%$ of neoplasms in the submandibular gland are benign and mostly PAs. Of the malignant tumors, adenoid cystic carcinoma is the most common. PAs, also known as benign mixed tumors, are the most common benign salivary gland tumors. They are classified as mixed tumors due to the epithelial and mesenchymal components of the neoplasm (1). Ectopic PAs can be observed in the paranasal sinuses, pharynx, larynx, and bronchi (2).

It is difficult to distinguish between benign and malignant neoplasms based on the clinical symptoms and radiologic examination (1). Pain due to benign tumor is reported in $2 \%-20 \%$ cases. The role of FNAB in diagnosis is controversial. Although FNAB is reliable in distinguishing between benign and malig- 
nant lesions, it does not provide accurate diagnosis as compared with definitive histopathological examination (7). In a study of 25 submandibular neoplasms by Ethunandan et al., FNAB accurately identified $78 \%$ benign tumors but no malignant tumors (7). FNAB before the surgery can be useful from a medicolegal perspective despite the perplexing importance of FNAB in salivary glands.

The decline in recurrent PA incidence may be due to the replacement of enucleation in parotid tumors with superficial lobectomies and total parotidectomies. Minor salivary gland and submandibular gland tumors are treated by total gland excision. For recurrent PA, there are several hypotheses based on histopathological and genetic factors as mentioned above. In a different series, the incidence of recurrence of parotid PA following the primary surgery was shown to be between $0.8 \%$ and $5 \%$. Recurrence is common after surgery for recurrent adenomas (3-6). Recurrences most often present with multilocular development and complete surgical excision is difficult.

Oudidi et al. (8) performed total gland excision without any recurrence. Roh and Park (9) evaluated 20 patients with PA, who were treated only with tumor extirpation, and found no recurrence at a median of 36 months after surgery. In contrast, Munir and Bradley (11) diagnosed 32 patients with PA in a 16-year period and performed extracapsullary excision on 13 of them and additional level 1b, 2a, and 3 neck dissections on 19 of them. There was no recurrence in these patients in their mean 10-month follow-up. They also identified 5 cases of patients with PA who were previously treated elsewhere. The patients with recurrent PA had previously undergone extracapsular submandibular gland excision at a different hospital. The recurrence time after initial surgery for these patients varied between 5 and 30 years. Three of these patients had multifocal, one had nodular, and one had two nodular recurrences. In the case presented herein, the recurrence was detected after 5 years and the multinodular lesions had a potato sack-like appearance on MR images. Ziglinas et al. (12) identified 41 submandibular gland tumor cases, of which 20 were benign and 21 were malignant. Of the 20 benign tumors, 17 were PAs. No recurrence was seen in more than 5-year follow-up. On the other hand, Alves et al. (13) identified 54 recent submandibular gland PA cases and found one case of recurrence at the 3-year follow-up. They treated four cases of recurrent PA. In two of them, both the submandibular gland and the tumor were excised. In the other two, only the tumor was resected because the gland had been removed previously. They also reported that although capsule invasion does not indicate malignant transformation, it may be a reason for recurrence. We decided to perform level 1-2-3 neck dissection considering the multinodular structure of the mass and to ensure complete excision. Marginal mandibular branch paralysis of the facial nerve was observed after the first operation; therefore, we assume that complete tumor excision or retention of the submandibular gland capsule integrity was difficult.

\section{Conclusion}

Although several cases of recurrent parotid gland PA have been reported in the literature, recurrent submandibular gland PA is quite rare. There are different hypotheses for the reason of recurrence. Complete surgical removal of tumor of the submandibular gland and keeping the capsule intact during surgery are important to prevent recurrence.

Informed Consent: Written informed consent was obtained from the patient.

Peer-review: Externally peer-reviewed.

Author Contributions: Concept - S.İ., E.A.; Design - E.Y.A.; Supervision - E.A.; Materials - S.İ., E.Y.A.; Data Collection and/or Processing - S.T.B.; Literature Search - S.I., S.T.B., E.Y.A.; Writing Manuscript -S.İ; Critical Review - E.A., S.T.B., E.Y.A.

Conflict of Interest: No conflict of interest was declared by the authors.

Financial Disclosure: The authors declared that this study has received no financial support.

\section{References}

1. Spiro RH. Salivary neoplasms: overview of a 35-year experience with 2807 patients. Head Neck Surg 1986; 8: 177-84 [CrossRef]

2. Seifert G, Miehlke A, Haubrich J, Chilla R. Diseases of the salivary glands. New York: Thieme, 1986, p. 408.

3. Donovan DT, Conley JJ. Capsular significance in parotid tumor surgery: reality and myths of lateral lobectomy. Laryngoscope 1984; 94: 324-32.

4. Soares AB, Altemani A, de Araújo VC. Study of histopathologi$\mathrm{cal}$, morphological and immunohistochemical features of recurrent pleomorphic adenoma: an attempt to predict recurrence of pleomorphic adenoma.J Oral Pathol Med 2011; 40:352-8. [CrossRef]

5. Henriksson G, Westrin KM, Carlsoo B, Silfversward C. Recurrent primary pleomorphic adenomas of salivary gland origin: intrasurgical rupture, histopathologic features, and pseudopodia. Cancer 1998; 82: 617-20.

6. Riad MA, Abdel-Rahman H, Ezzat WF, Adly A, Dessouky O, Shehata M. Variables related to recurrence of pleomorphic adenomas: outcome of parotid surgery in 182 cases. Laryngoscope 2011; 121: 1467-72. [CrossRef]

7. Ethunandan M, Davies B, Pratt CA, Puxeddu R, Brennan PA. Primary epithelial submandibular salivary gland tumours - review of management in a district general hospital setting. Oral Oncol 2009; 45: 173-6. [CrossRef]

8. Oudidi A, El-Alami MN, Boulaich M, Jazouli N, Kzadri M. Primary submandibular gland tumors: experience based on 68 cases. Rev Laryngol Otol Rhinol (Bord) 2006; 127: 187-90.

9. Roh JL, Park CI. Gland-preserving surgery for pleomorphic adenoma in the submandibular gland. Br J Surg 2008; 95: 1252-6.

10. Spiro JD, Spiro RH. Submandibular gland tumours. In: Shockley WW (ed) The neck: diagnosis and surgery. Mosby, USA, 1994. pp 295-306.

11. Munir N, Bradley PJ. Pleomorphic adenoma of the submandibular gland: an evolving change in practice following re- 
view of a personal case series. Eur Arch Otorh 2007; 264: 1447-52.

12. Ziglinas P, Arnold A, Arnold M, Zbären P. Primary tumors of the submandibular glands: a retrospective study based on 41 cases. Oral Oncol 2010; 46: 287-91. [CrossRef]
13. Alves FA, Perez DE, Almeida OP, Lopes MA, Kowalski LP. Pleomorphic adenoma of the submandibular gland clinicopathological and immunohistochemical features of 60 cases in Brazil. Arch Otolaryngol Head Neck Surg 2002; 128: 1400-3. 